\title{
Incidence of malignancy of nasopharyngeal swellings in adults
}

\author{
Mahmoud Sayed Abed elrahmanmohmed
}

\begin{abstract}
Introduction: Nasopharyngeal mass resembles a confounding problem in adults because of the increased fearof malignancy with age advancement. Histopathological pattern of nasopharyngeal lesions varies from commonbenign lesions such as hyperplastic lymphoid tissue and benign nasopharyngeal cysts to malignant diseases suchas lymphoma and nasopharyngeal carcinoma.
\end{abstract}

Methods: This prospective study included all patients underwent a nasopharyngeal biopsy for a nasopharyngealmass in 2 years period from June 2014 to June 2016. Blind biopsy was taken for cases clinically suspiciousfor having nasopharyngeal carcinoma. Patients histopathological findings were analyzed as regard demographic data and clinical presentation.

Results: A total of 100 patients (54 males and 46 females) were included.Patient age ranged between 18 and 76 years (mean 39.37 years, SD 1.628). The most commonly detectedpathological lesion was hyperplastic lymphoid tissue hyperplasia (59\%). Malignant lesions constituted $39 \%$ ofthe study population $(10 \%$ squamous cell carcinoma, $14 \%$ undifferentiated carcinoma and 15\% malignantlymphoma). In addition, benign nasopharyngeal cysts were diagnosed in $2 \%$ of cases.

Conclusion: Benign lesions are more commonly detected in the nasopharynx in adult population particularlyhyperplastic lymphoid tissue. Histopathological examination ofnasopharyngeal mass is very essential to roll outmalignancy which is not uncommon.

Keywords: Nasopharyngeal; Lymphoid hyperplasia; Carcinoma; Lymphoma; Histopathology

\section{Introduction}

Detection of mass in the nasopharynx of an adult is usually associated with suspicion of nasopharyngeal malignancy [1]. Malignant diseases arising in the nasopharynx are asymptomatic in the early stage and may be confused with other benign lesions; therefore Patients with nasopharyngeal malignancy usually come with late presentation [2].

Adenoid tissue regression usually occurs at adolescence; however itmay persist in adults causing significant nasal obstruction and histopathological examination is required to preclude the possibility of malignancy $[1,3,4]$.
Benign lesions in the nasopharynx of adults also include cystic lesions such as branchial cleft cyst, Tornwaldt cyst and mucous retention cyst $[5,6]$. In this study we identify the various pathological entities detected in adult patients presented to our department with a swelling with analysis of the associated clinical and demographic data

\section{Methods}

This is a prospective study of adult population (starting from 18years) undergoing endoscopic guided nasopharyngeal biopsy to exclude nasopharyngeal malignancy from June 2014 to June 2016 in our tertiary referral center. Institutional review board approval was obtained. All 
patients included in the current study presented to our outpatient clinic with nasopharyngeal masses. All cases ofantrochoanal polyps and angiofibroma were excluded from the study. Demographic data (Age, gender, smoking status), clinical picture(presenting symptoms and signs) and clinical findings onnasopharyngeal endoscopy were recorded. Nasopharyngeal biopsieswere obtained under general anesthesia. A $4 \mathrm{~mm}$ rigid endoscope wasintroduced through the inferior meatus till clearly visualizing thenasopharynx. A good view of the nasal cavity and the nasopharynxwas possible in all cases and biopsy was performed using a punchforceps. Pathology reports were reviewed for biopsy results.Descriptive analysis was used for frequencies and means. Analysis wasconducted using SPSS (SPSS Inc, Chicago, IL) and a $\mathrm{p}$ value $<0.05$ wasconsidered significant (Figures 1 and 2).

Ethics, Consent and Permissions

Institutional review board approval was obtained from ethical committee at Sohag University, Egypt. All study population were consented for participation in the study.

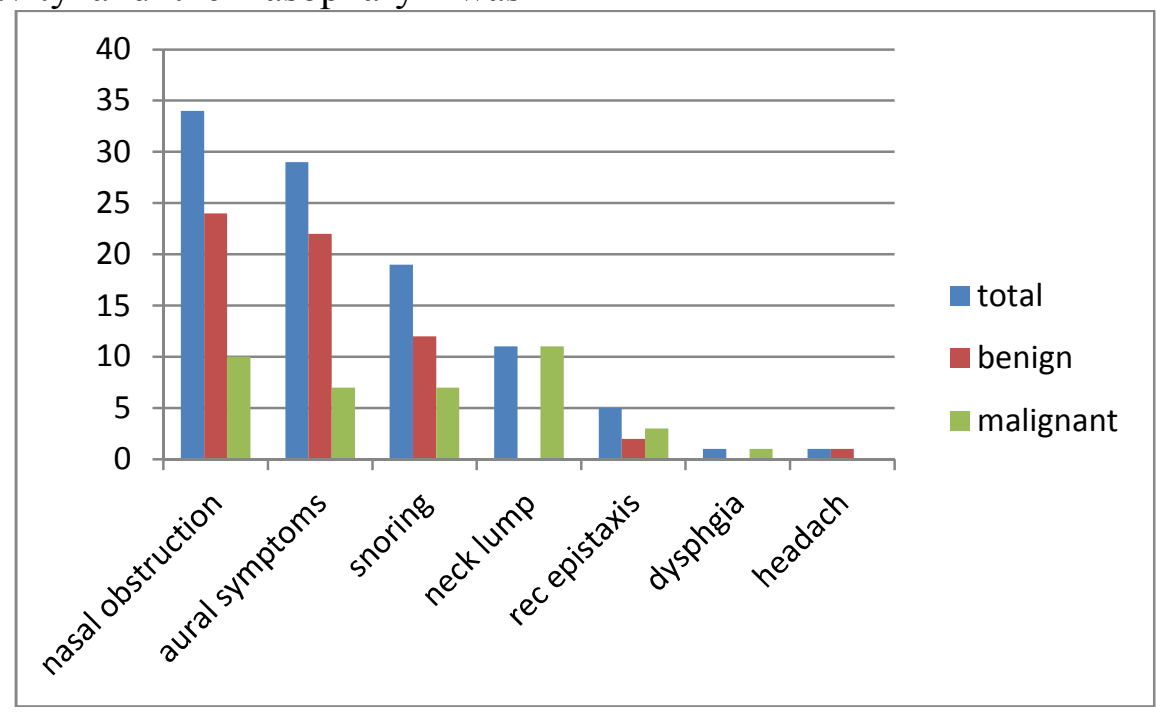

Figure 1: Distribution of the presenting symptoms in adult patients with nasopharyngeal mass. 


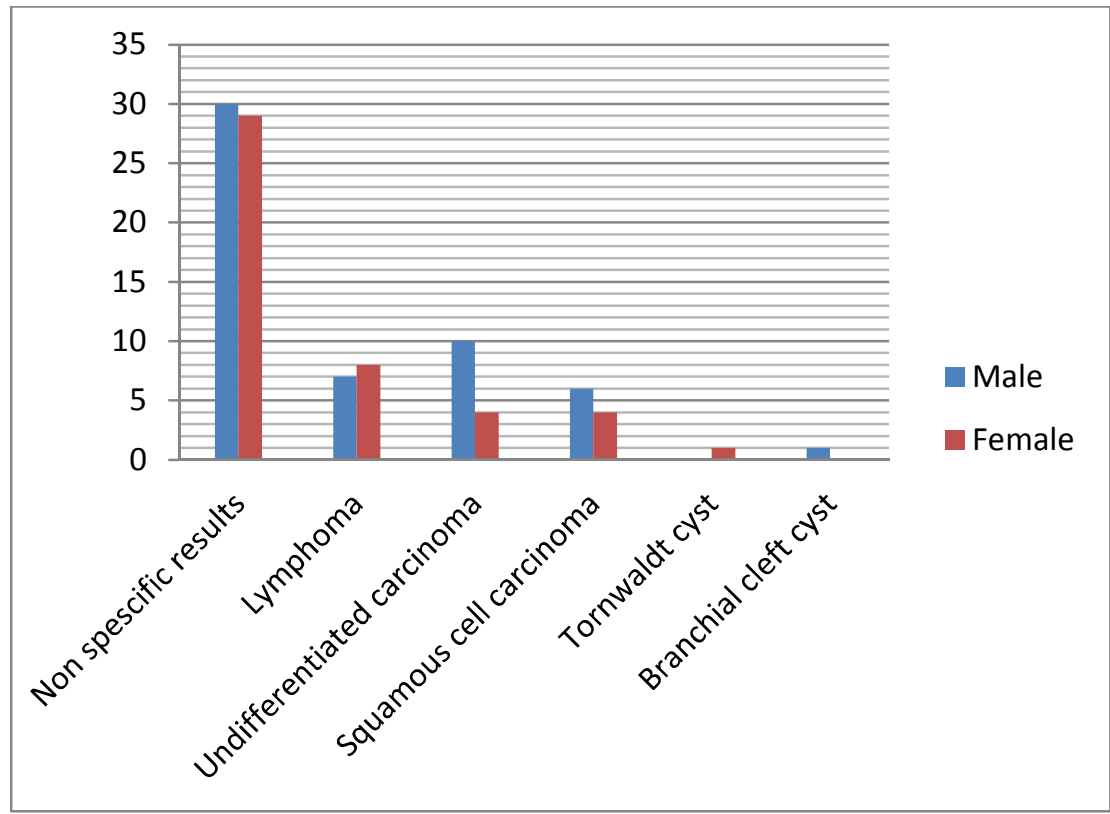

Figure 2: Different pathological legions encountered in adult nasopharynx and difference in prevalence between both sexes.

\section{Results}

A total of 100 patients (54 males- 54\% and 46 females- $46 \%$ ) were included in our study. Patients' age ranged between 18 and 76 years (mean $\pm \mathrm{SD}=45.1 \pm 13.6$ years). Histopathological examinationof nasopharyngeal biopsies revealed diversity of benign and malignant lesions. The detected benign pathological lesions included hyperplastic lymphoid tissue hyperplasia (59\%), Tornwaldt cyst (2\%) and Branchial cleft cyst (2\%). Malignant lesions constituted $39 \%$ of the study population $(10 \%$ squamous cell carcinoma, $14 \%$ undifferentiated carcinoma and 15\% malignant lymphoma) (Tables 1and 2).

\begin{tabular}{|l|l|l|l|l|}
\hline Pathology & Number of cases & Percentage & Male & Female \\
\hline $\begin{array}{l}\text { Hyperplastic lymphoid tissue } \\
\text { (Adenoid and other } \\
\text { inflammatory results) }\end{array}$ & 59 & $59 \%$ & 30 & 29 \\
\hline Thornwaldt's cyst & 1 & $1 \%$ & 0 & 1 \\
\hline Branchial cleft cyst & 1 & $1 \%$ & 1 & 0 \\
\hline Lymphoma & 15 & $15 \%$ & 7 & 8 \\
\hline Undifferentiated carcinoma & 14 & $14 \%$ & 10 & 4 \\
\hline Squamous cell carcinoma & 10 & $10 \%$ & 6 & 4 \\
\hline Total & 100 & $100 \%$ & 54 & 46 \\
\hline
\end{tabular}

Table 1: Illustrates the numbers and percentages of different pathological nasopharyngeal lesions in the whole study population and numbers in each sex group. 
SOHAG MEDICAL JOURNAL Incidence of malignancy of nasopharyngeal swellings in adults

\begin{tabular}{|c|c|c|c|}
\hline Presenting symptom & $\begin{array}{c}\text { Number } \\
\text { (percentage } \%)\end{array}$ & $\begin{array}{c}\text { Number } \\
\text { (percentage } \% \text { ) of } \\
\text { benign cases }\end{array}$ & $\begin{array}{c}\text { Number } \\
\text { (percentage } \% \text { of } \\
\text { malignant cases }\end{array}$ \\
\hline Nasal obstruction & $34(34 \%)$ & $24(24 \%)$ & $10(10 \%)$ \\
\hline Aural symptom & $29(29 \%)$ & $22(22 \%)$ & $7(7 \%)$ \\
\hline Snoring & $19(19 \%)$ & $12(12 \%)$ & $7(7 \%)$ \\
\hline Neck lump & $11(11 \%)$ & $\begin{array}{ll}0 & (0 \%)\end{array}$ & $11(11 \%)$ \\
\hline Rec epistaxis & $5(5 \%)$ & $2(2 \%)$ & $3(3 \%)$ \\
\hline Dysphagia & $1(1 \%)$ & $0 \quad(0 \%)$ & $1(1 \%)$ \\
\hline Headache & $1(1 \%)$ & $1(1 \%)$ & $\begin{array}{ll}0 & (0 \%)\end{array}$ \\
\hline Total & $100(100 \%)$ & $61(61 \%)$ & $39(39 \%)$ \\
\hline
\end{tabular}

Table 2: Illustrates the distribution of patients main complaints in the whole study population and separately in malignant and benign lesions.

The duration of complaint ranged from six months to six years at time of presentation for benign lesions and from one month to one year in malignant lesions. Out of 39 patients with malignant lesions 14 were smokers (all males); 6 patients had undifferentiated carcinoma, 5 had lymphoma and 1 had squamous cell carcinoma; however only 11 patients (all males) were smokers in the benign group. The mean age for patients having malignant lesions was 48.4 years with minimum 21 years and maximum 65 years.

There was no significant data regarding patient's jobs, or their residence.

Nine patients having malignant nasopharyngeal swellings presented with unilateral secretory otitis media while two patients presented with bilateral secretory otitis media. Only 2 cases with benign pathology had unilateral secretory otitis media, other cases had bilateral conditions including unsafe ear, central perforations and adhesive otitis media.

\section{Discussion}

The symptoms associated with nasopharyngeal malignancy are often vague and non specific which causes late diagnosis of the disease usually in an advanced stage [7]. Nasopharyngeal malignancy may be confused with enlarged nasopharyngeal lymphoid tissue in adults. The cause of adenoid hypertrophy in adults is not clearly understood; many factors are blamed including viral or bacterial infection with reactive lymphoid hyperplasia and external irritants such as dust, smoking and allergic disorders [1].

Routine nasopharyngeal endoscopic examination is not reliable to distinguish between malignant lesions and adenoid tissue in adults, the standard medical practice is to biopsy nasopharyngeal masses for histopathological examination [1,7].

Kamel and Ishak in 1990 reported exclusion of malignancy in many adult patients with nasopharyngeal masses and the diagnosis was made as chronic adenoiditis [1].

A study conducted in 2002 and included 30 cases reported a 15:1 ratio of benign: malignant nasopharyngeal masses; the study included both adults and children. Another study published in 2014 and included only adults starting from the age of 18 years 
reported an 18:1 ratio of benign: malignant nasopharyngealmasses [8,9].

In this study malignant nasopharyngeal diseases constituted 39 $\%$ of the group population which is markedly more than the percentage reported in other recent studies [8,9].

The hypertrophy of nasopharyngeal lymphoid tissue is reported in the first 4 years of life and its involution usually happens by the age of 6 to 16 years [10]. The reported aetiopathogenetic factors responsible for adenoid hypertrophy in adults included persistence of childhood adenoids due to chronic inflammation or re-growth of involuted adenoidal tissue as a result of irritants, infections or smoking. Studies also reported viral infection in immunocompromised patients particularly HIV infection or after organ transplantation $[1,11]$.

The importance of age in assessing nasopharyngeal masses cannot be denied as malignant diseases usually develop later in life while benign masses are usually identified at a younger age. In our study, the mean age of adult patients with benign disease was $45.08 \pm 15.6$ years, while that of patients with malignant disease was $49.51 \pm 12.06$ years; this difference was significant $(p<0.001)$. Meanwhile we should not forget that malignant nasopharyngeal disease was detected at young age of 21 years.

In this study we found no significant sex difference as regard adultadenoid hypertrophy, also any significant effect of smoking orimmunodeficiency was not observed. We found important genderdifference as regard development of malignant tumors where the maleto female ratio was $2: 1$ however in patients with benign pathology themale to female ratio was $1: 1.15$.

The presence of a mass in the nasopharynx of an adult raises the suspicion for malignant disease; the coincidence of unilateral secretory otitis media is another warning sign for ruling out nasopharyngealcancer [11]. presentation in malignant group was neck lump and aural symptoms followed by The complaint of nasal obstruction and snoring was significantly higher in patients with benign lesions $(24 \%$ and $12 \%$,respectively) than in patients with malignant lesions $(10 \%$ and $7 \%)$. The most common nasal obstruction. Our results are in accordance to the literature evidence that unilateral OME increases suspicion for nasopharyngeal malignancy and the necessity of nasopharyngeal biopsy in those patients [12].

In 1997 Johannsson and his colleagues found that NPC was the most common malignant nasopharyngeal disease $(82 \%)$, followed by plasmacytoma (4\%), lymphoma $\quad(3 \%) \quad$ and rhabdomyosarcoma (1\%) [13]. Other studies in 1983 and in 2014 found that NPC was the mostcommon malignancy, followed by lymphoma, which is similar to ourresults [2,9].

In this study found that reactive lymphoid hyperplasia is the most common pathology encountered in the nasopharynx of adult population followed respectively by nasopharyngeal carcinoma andnasopharyngeal lymphoma while nasopharyngeal cysts were the least detected lesions.

\section{Conclusion}

Benign lesions are more commonly detected in the nasopharynx in adult population particularly hyperplastic lymphoid tissue. Histopathological examination of nasopharyngeal mass is veryessential to rule out malignancy which is not uncommon. 


\section{References}

1. Kamel RH, Ishak EA (1990) Enlarged adenoid and adenoidectomy in adults: Endoscopic approach and histopathological study. J LaryngolOtol 104: 965-967.

2. Hopping SB, Keller JD, Goodman ML, Montgomery WW

Nasopharyngeal masses in adults. Ann OtolRhinolLaryngol 92: 137-140.

3. Wang $\mathrm{WH}$, Lin $\mathrm{YC}$, Weng $\mathrm{HH}$, Lee KF (2011) Narrow-band imaging for diagnosing adenoid hypertrophy in adults: A simplified grading and histologic correlation. Laryngoscope 121: 965-970.

4. Mattila PS, Tarkkanen J (1997) Ageassociated changes in the cellular composition of the human adenoid. Scand J Immunol 45: 423-427.

5. Chang ET, Adami HO (2006) The enigmatic epidemiology of nasopharyngeal carcinoma. Cancer Epidemiol Biomarkers Pre 15: 17651777.

6. Sekiya K, Watanabe M, Nadgir RN, Buch K, Flower EN, et al. (2014) Nasopharyngeal cystic lesions: Tornwaldt and mucous retention cysts of the nasopharynx: Findings on MR imaging. J Comput Assist Tomogr 38: 9-13.

7. Abu-Ghanem S, Carmel NN, Horowitz G, Yehuda M, Leshno M, et al. (2015) Nasopharyngeal biopsy in adults: A large-scale study in a non endemic area. Rhinology 53: 142-148.

8. Biswas G, Ghosh SK, Mukhopadhyay S, Bora H (2002) A clinical study of nasopharyngeal masses. Indian $\mathrm{J}$ Otolaryngol Head Neck Surg 54: $193-$ 195.

9. Berkiten G, Kumral TL, Yildirim G, Uyar Y, Atar Y, et al. (2014) Eight years of clinical findings and biopsy results of nasopharyngeal pathologies in 1647 adult patients: A retrospective study. B-ENT 10: 279-284.

10.Brodsky L, Koch RJ (1993) Bacteriology and immunology of normal and diseased adenoids in children. Arch Otolaryngol Head Neck Surg 119: 821-829.

11. Yildirim N, Sahan M, Karslioğlu Y (2008) Adenoid hypertrophy in adults: Clinical and morphological characteristics. J Int Med Res 36: 157162.

12.Glynn F, Keogh IJ, Ali TA, Timon CI, Donnelly M (2006) Routine nasopharyngeal biopsy in adults presenting with isolated serous otitis media: Is it justified? J LaryngolOtol 120: 439-441.

13.Johannsson J, Sveinsson T, Agnarsson BA, Skaftason S (1997) Malignantnasopharyngeal tumours in Iceland. ActaOncol 36: 291-294. 